DRCOG etc). It is for the Examination Committee to decide how changes should be implemented.

University of Leicester

V. M. MATHEW

Leicester Royal Infirmary

Leicester LE2 $7 L X$

\section{Dear Sirs}

Being an overseas trainee working on the overseas doctors training scheme, I fully support the points made by Dr Mathew (Psychiatric Bulletin, 1991, 15, 699-700). I feel that he has raised an important issue. It would indeed be impossible for all those overseas trainees who wish to take membership examination to make the full number of attempts for their Part I and Part II of the MRCPsych.

Being allowed to stay in the UK for only four years will certainly cause a lot of anxiety among those candidates who fail to pass within the first few attempts. The Dean and the Chief Examiner in their reply have pointed out that most of the overseas trainees do not want to take the MRCPsych examination which I think is not true. Given the chance to take the examination, most of the doctors will wish to get a high class British qualification. The suggestion of an alternative examination is very good and the College should consider it seriously.

The Dean and the Chief Examiner have also mentioned that it would involve a lot of expenditure to conduct such an examination. As far as the financial aspect is concerned, I think that the College can recover a handsome amount of money from the candidates in respect of fees. Introduction of the DPM or any equivalent qualification would especially be of benefit to those who are limited to a few years in the United Kingdom or who are unable to pass the MRCPsych examination.

The College may not agree with the idea of unlimited attempts for DPM but this examination can be organised according to the standards set by the College.

MRCPsych is undoubtedly the most prestigious qualification and even if the DPM examination is started its value would not diminish, so at least some consideration should be given to this idea.

Leicester General Hospital

RAMEEZ ZAFAR

\section{Leicester LE5 4PW}

DeAR SirS

Thank you for giving us the opportunity of reading Dr Zafar's letter.

I think that reference to our reply will indicate that we said many overseas trainees, not most will not wish to take MRCPsych seriously. The question of an alternative examination is being considered by the College as we indicated.

With regard to the financial aspects, as Dr Zafar points out, it might well be possible to make a new examination self-financing, but money is not the only matter to be considered. The setting up of any new examination takes other resources, particularly space and personnel, and this has to be considered with respect to the College generally.

Dr Sheila A. ManN Chief Examiner Dr Fiona CaldicotT Dean

\section{Requirements for submission of medical articles}

\section{DeAr Sirs}

The recent correspondence about requirements for submission of medical articles (Psychiatric Bulletin, $1991,15,703$ ) highlights the need for a review of the current system and a widening of the current debate. The prevalence of disputes among authors is unknown. Up to now authors have operated an honour system and are assumed to have discussed alterations and the order of authors. Problems can occur with junior doctors who are under increasing pressure to publish in order to further their careers. It may not always be clear to them what standards apply. Some journals require written permission from all authors before they will publish. Perhaps journals should have a set of guidelines which are sent to the authors on acceptance of an article. These could include confirmation that the order of authorship has been agreed and reflects an appropriate input into the article and that all authors have seen the final draft of the article. The originality and authenticity of the research should also be confirmed. A consensus in guidelines among editors of journals would also help limit confusion.

Research determines a major part of a junior doctor's career progression. This results in pressure to publish which can lead to inadequate and poorly supervised research. The proliferation of medical journals is testament to this. Perhaps appointments committees could also limit the number of papers a candidate could cite.

\section{Wolfson Building}

VIVIENNE SCHNIEDEN

London WIN 8

Editorial note. Our Notice to Contributors now states that all material submitted for publication to the Psychiatric Bulletin should be accompanied by a covering letter to the editors signed by all authors.

\title{
When relatives refuse to give consent
}

DeAr SiRS

With regard to the letter concerning the use of the Mental Health Act 1983 from Jon Kennedy (Psychiatric Bulletin, 1991, 15, 701), I would like to comment 